\title{
Amizades de universitários cabo-verdianos no Brasil
}

\section{Friendships of Cape-Verdean college students in Brazil}

\author{
Agnaldo Garcia ${ }^{[a]}$, Paula Maria Valdetaro Rangel ${ }^{[b]}$
}

[a] Departamento de Psicologia Social e do Desenvolvimento e Programa de Pós-Graduação em Psicologia da UFES, Doutor em Psicologia pela Universidade de São Paulo (USP), bolsista de Produtividade em Pesquisa do CNPq, Serra, ES - Brasil, e-mail: agnaldo.garcia@pq.cnpq.br

[b] Aluna do curso de Psicologia da Universidade Federal do Espírito Santo (UFES), bolsista de Iniciação Científica do CNPq.

\section{Resumo}

O presente trabalho investigou amizades de universitários cabo-verdianos residindo e estudando no Brasil. Participaram da pesquisa 12 alunos de graduação da Universidade Federal do Espírito Santo que foram entrevistados. Os participantes citaram 109 amigos, sendo 81 cabo-verdianos, 18 brasileiros e seis angolanos, além de um português, um guineense, um santomense e um hondurenho. Os idiomas mais utilizados com amigos foram o crioulo e o português. A maioria dos amigos (72) residia na Grande Vitória. Entre os 35 amigos mais próximos, 24 eram conhecidos de Cabo Verde. Os principais interesses comuns e atividades compartilhadas estavam associados a estudo e lazer. Os amigos mais próximos foram descritos com base em características pessoais, seu significado e o relacionamento com o participante, destacando o valor da amizade e a ajuda recebida. Quando dificuldades foram citadas, estas se referiam à distância dos amigos, características pessoais e dificuldades de comunicação. Os episódios marcantes estavam ligados a lazer e ajuda do amigo. A maioria das amizades foi relevante para a adaptação ao Brasil, mas apenas parte delas influenciou a forma de ver o País. Finalmente, é apontada a necessidade de ações da universidade para facilitar a construção de amizades entre estudantes cabo-verdianos e brasileiros, possibilitando uma maior integração social e cultural como base para um aprofundamento de relações de cooperação científica e cultural entre os países.

Palavras-chave: Amizade. Universitários. Cabo verde.

\section{Abstract}

This study focuses on friendships of college students from Cape Verde living and studying in Brazil. Twelve CapeVerdean undergraduate students from the Federal University of Espirito Santo were interviewed. The students mentioned 109 friends, including 81 Cape Verdeans, 18 Brazilians, six Angolans, one Portuguese, one Guinean, one Santomean and one Honduran. The most widely used languages with friends were Creole and Portuguese. Most friends (72) lived in the Metropolitan Vitoria. Among the 35 closest friends, 24 were known from Cape Verde. 
The main common interests and shared activities were associated with study and leisure. The closest friends were described based on personal characteristics, their significance and relationship with the participant, highlighting the value of friendship and assistance received. When difficulties were mentioned, these were related to distance from friends, personal characteristics and communication difficulties. Outstanding episodes were linked to leisure and help from friends. Most friendships were related to adaptation to Brazil, but only part of them influenced how they perceived the country. Finally, it pointed out the necessity of actions from universities to facilitate the development of friendships between Cape Verdeans and Brazilians fostering a larger social and cultural integration as the basis for deepening scientific and cultural cooperation between the countries.

Keywords: Friendship. College students. Cape Verde.

\section{Introdução}

As amizades entre pessoas de diferentes etnias, países ou culturas ainda são pouco conhecidas, especialmente no contexto brasileiro. Essas, contudo, são relevantes por motivos teóricos e práticos. Amizades internacionais pessoais possivelmente contribuem para a ampliação de amizades internacionais entre países, aumentando as trocas e a cooperação internacional. Do ponto de vista teórico, a possibilidade de amizade entre pessoas pertencentes a diferentes nações e culturas é um tópico relevante da pesquisa sobre amizade, a qual geralmente tem como base a similaridade entre amigos. Amizades entre pessoas de diferentes raças, etnias ou culturas é um fenômeno que merece mais atenção.

Questões raciais e étnicas afetam as amizades (Antonio, 2004). A identificação racial, por exemplo, favorece a escolha de amigos (Kao \& Vaquera, 2006), os laços de amizade e as atividades compartilhadas (Kao \& Joyner, 2004). Amizades interculturais também estão associadas à sensibilidade multicultural e à competência social (Hunter \& Elias, 1999), levando a atitudes mais favoráveis em relação a outras raças, como no caso da aprovação de casamentos interraciais (Jacobson \& Johnson, 2006).

O tema central nos estudos sobre amizades de estudantes universitários no exterior tem sido as dificuldades em estabelecer amizades com habitantes do país anfitrião e a formação de amizades com pessoas do mesmo país ou etnia (Bailey, 2006; Brown, 2009a, Pandian, 2008; Cushner \& Karim, 2004; Sawir, Marginson, Deumert, Nyland \& Ramia, 2008; United Kingdom Council for International Education, 2004). Enquanto as amizades com conterrâneos fornecem apoio instrumental e reduzem o estresse, aquelas com pessoas do país anfitrião ajudariam na aprendizagem do idioma e da cultura local (Brown, 2008; Ward, Bochner \& Furnham, 2001).

Maundeni (2001), em pesquisa sobre a adaptação de universitários africanos no Reino Unido, concluiu que amigos do mesmo país podem prover ajuda prática, informações relevantes para a sobrevivência no local, apoio emocional e espiritual, além de compartilhamento de identidade e valores culturais. A convivência com pessoas do mesmo país, contudo, pode dificultar a aprendizagem do idioma, e a formação de grupos de estrangeiros de um mesmo país podem dar origem à discriminação. De acordo com Zhao e Wildemeersch (2008), o relacionamento com pessoas do mesmo país representa uma fonte importante de apoio emocional e social para esses estudantes diante de uma possível superficialidade nos relacionamentos com pessoas do país anfitrião.

As amizades interculturais ou internacionais ainda poderiam aumentar a tolerância em relação a outras culturas (Cushner \& Karim, 2004). Contudo, pesquisas têm indicado que a melhoria nas habilidades transculturais ou o aumento da competência intercultural têm sido menores que o esperado (Ward, 2001; Brown, 2009b).

No Brasil, há poucas informações sobre amizades de estudantes estrangeiros. A amizade tem sido mencionada de passagem em pesquisas sobre outros aspectos da vida desses estudantes. Desidério (2006), por exemplo, citou a formação de amizades com brasileiros como um dos principais problemas encontrados por universitários estrangeiros no Brasil. Subuhana (2009), por outro lado, ao investigar a experiência sociocultural de universitários africanos no Brasil, referiu-se à integração e amizade com os brasileiros como fatores positivos dessa experiência.

A amizade, além de ser um importante fator para o desenvolvimento afetivo, cognitivo e 
social, também contribui para o desenvolvimento da cooperação social, cultural e científica entre cidadãos de diferentes países. O presente estudo apresenta relevância científica ao tratar de amizades entre pessoas com diferenças culturais. Do ponto de vista empírico, faltam pesquisas sobre amizades internacionais e interculturais, especialmente no contexto latino-americano. Do ponto de vista social, visa a contribuir para a integração social e a cooperação científica e cultural envolvendo universitários estrangeiros em nosso país. Os resultados auxiliarão a desenvolver programas de inserção social desses universitários, abrindo novas possibilidades de interação e cooperação internacional, contribuindo para a formação de uma sociedade internacional baseada em princípios de direito, justiça e igualdade entre os povos.

Entre os autores que têm contribuído para a construção de uma "ciência do relacionamento interpessoal" destaca-se Robert Hinde. Esse autor enfatizou a importância de uma base descritiva na pesquisa sobre o relacionamento, a busca de processos subjacentes à dinâmica dos relacionamentos e a consideração de diversos níveis de complexidade (Hinde, 1997). Adams e Blieszner (1994) propuseram um modelo teórico para a amizade de adultos incluindo a investigação de aspectos internos e externos, ao lado de aspectos estruturais e processos, integrando a perspectiva sociológica e a psicológica. As propostas desses autores servirão de referencial teórico mais amplo para a presente investigação.

Esta pesquisa teve como objetivo geral identificar, descrever e analisar alguns aspectos das amizades de universitários de Cabo Verde residindo no Brasil, visando a contribuir para a integração social e cultural desses estudantes. Os objetivos específicos foram investigar: (a) a rede de amigos e suas propriedades (participantes, atividades compartilhadas, interesses comuns e comunicação); (b) o relacionamento com os três amigos mais próximos (histórico da amizade e percepção do amigo, dificuldades e o significado dessa amizade, seu papel para a adaptação ao Brasil e a percepção do País). Atingir esses objetivos contribuirá para integrar esses universitários e fomentar a cooperação cultural e científica.

Segundo Desidério (2006), há 1.630 estudantes universitários africanos no Brasil, sendo 1.386 de graduação e 244 de pós-graduação, incluindo angolanos (732 estudantes), cabo-verdianos (439), moçambicanos (166), sul-africanos (63) e guineenses (58).

\section{Métodos}

Participaram da pesquisa 12 universitários de Cabo Verde, com idades entre 19 e 30 anos, regularmente matriculados em diferentes cursos de graduação da Universidade Federal do Espírito Santo. Em que ano? Havia cinco homens e sete mulheres e o tempo de estadia no Brasil variou de seis meses a sete anos. Sete deles possuíam parentes no Brasil, geralmente um irmão ou irmã. Os estudantes participavam do Programa de Estudantes Convênio de Graduação (PEC-G).

Quanto ao procedimento de coleta de dados, estes foram obtidos por meio de entrevistas semiestruturadas, com base em um roteiro preestabelecido, contendo perguntas fechadas e abertas. Os participantes foram entrevistados individualmente e os dados foram gravados e transcritos. Os alunos foram contatados, inicialmente, a partir de informações cedidas pela Pró-Reitoria de Graduação da universidade e, posteriormente, a partir de indicações dos próprios entrevistados. Após um primeiro contato (por e-mail e/ou telefone), era agendada uma entrevista com aqueles que aceitavam participar da pesquisa, que assinavam um Termo de Consentimento de Participação em Pesquisa.

Os dados transcritos das entrevistas foram analisados por análise de conteúdo, com base em Bardin (1977), sendo organizados em categorias de acordo com a literatura sobre o tema. Dentro de cada categoria de análise foram propostas subcategorias, de modo indutivo, a partir dos dados obtidos.

O roteiro de entrevista utilizado constava de três partes:

1) Dados sócio-demográficos do participante (nacionalidade, local de nascimento, idade, tempo de residência no Brasil, curso e período que está matriculado, idiomas e familiares no Brasil);

2) A rede de amigos: (a) identificação dos amigos: gênero, idade, país de origem e breve histórico da amizade; (b) atividades compartilhadas e interesses comuns; (c) a comunicação com amigos (idiomas e meios de comunicação);

3) O relacionamento com os amigos mais próximos (até três) quanto à percepção desse amigo (descrição do amigo), ao histórico da amizade (incluindo os 
episódios mais marcantes e o último contato), onde reside (Brasil ou exterior), dificuldades e o significado dessa amizade e seu papel na adaptação ao Brasil e na forma como vê o Brasil.

\section{Resultados}

Os 12 participantes citaram de seis a dez amigos cada, totalizando 109 amigos com idades entre 18 e 33 anos, sendo 81 cabo-verdianos, 18 brasileiros, seis angolanos e ainda um guineense, um santomense, um português e um hondurenho. Em 16 amizades, mais de um idioma era utilizado para a comunicação com o amigo. $O$ português era utilizado em 30 relacionamentos e o crioulo em 63.

Onze participantes tinham pelo menos um amigo que residia na mesma cidade ou região metropolitana, totalizando 72 amigos, além de 15 amigos residindo em outras cidades brasileiras. Dez amigos residiam em Cabo Verde e seis em Portugal. Outros ainda residiam nos EUA (três) e Bolívia, Ilhas Canárias e São Tomé e Príncipe (um em cada país).

Os principais interesses ou atividades compartilhadas foram o lazer (91 amizades), os estudos (65 amizades), ciência e cultura (40), esportes (40), trabalho (17) e religião (13). O lazer inclui atividades como sair, conversar, ir à praia, ouvir música, cuidar de animais, passear, ir a festas, shopping centers, cinema, ver filmes, ir a restaurantes, teatros, fazer compras, ler um livro e discuti-lo com o amigo, ver um jogo, viajar juntos, assistir à TV juntos, beber juntos, jogar futebol, almoçar ou cozinhar em companhia do amigo. Quanto aos estudos, citaram o interesse comum de estudar no Brasil, concluir o curso e se graduar e voltar para o país de origem. Ainda compartilhavam o interesse de tentar mestrado ou especialização, trabalhar no país de origem e continuar vivendo ou trabalhando com o amigo, além de fazer trabalhos escolares, assistir aulas juntos, estudar em companhia do amigo e mesmo ir e voltar da universidade com o amigo.

O relacionamento com os três amigos mais próximos foi examinado em maior detalhe, contemplando a rede de amigos próximos, o histórico da amizade, a percepção do amigo, dificuldades e o significado dessa amizade, seu papel para a adaptação ao Brasil e a percepção do país. Cada participante podia citar até três amigos. No total, os doze participantes citaram 35 amigos mais próximos. Apenas um participante se limitou a citar dois amigos. O país de origem dos amigos mais próximos foi Cabo Verde (30 amigos), Brasil (4) e Angola (1). A maioria residia no Brasil, sendo 21 na mesma região metropolitana e sete em outras cidades brasileiras. Quatro residiam em Cabo Verde, dois nos EUA e um em Portugal.

$\mathrm{Na}$ descrição do amigo, foram utilizadas características pessoais, referências ao significado do amigo e propriedades do relacionamento com o participante, destacando o lado positivo da amizade. Quanto às características pessoais, o amigo foi descrito como compreensivo, legal, simpático, dócil, sempre disposto a ajudar, pessoa de confiança, participativo, que gosta de conversar, compromissado, responsável, sem vícios, prestativo, carinhoso, incentivador, apoiador, "gente fina", sincero, companheiro, conselheiro (ao dividir o dia a dia, dar opiniões, dividir todos os momentos), delicada, meiga, alegre, muito doida ou doidinha (pessoa divertida), pessoa inesquecível. E ainda sempre disposta a dar tudo para o participante, com quem sempre se pode contar, uma das melhores pessoas que conhece. Referiram-se também à similaridade ou afinidade entre os amigos: têm os mesmos hábitos ou o amigo tem tudo a ver com o participante. Quando a descrição indicava um ponto negativo, geralmente havia uma justificativa ou alguma informação atenuando essa condição negativa, como ser "um pouco" exaltado ou "um pouco" difícil de lidar, "um pouco" fechado ou teimoso "como eu". Mencionam conflitos com o amigo, mas informam que estes são resolvidos.

Quanto ao significado da amizade, enfatizaram o fato de ser amigo ou amigão, grande amigo, o melhor amigo, amiga muito querida ou alma gêmea de amizade. O amigo ainda foi considerado importante, "tudo", um tesouro, "minha vida", uma das coisas boas que aconteceu na vida, "meu pilar". Em vários momentos, o amigo assume o significado de um ente familiar, como pai, irmão ou irmã e filha. A ajuda recebida também foi destacada, particularmente a ajuda para adaptar-se ao Brasil. As propriedades do relacionamento apontadas indicaram uma relação profunda, de respeito, confiança, de dar-se bem, relação muito aberta, íntima, uma amizade profunda ou forte.

Dos amigos mais próximos, 24 haviam sido conhecidos por contato pessoal no exterior e 11 no Brasil. A maioria se conheceu em Cabo Verde, antes de vir estudar no Brasil. Alguns se conheciam desde a infância, morando na vizinhança, ou se 
conheceram no ensino médio. Outros foram conhecidos no processo de seleção para a universidade ou no trabalho. Quando se conheceram no Brasil, isto se deu na própria universidade, por vezes na mesma turma. Outros, porém, vieram em momentos diferentes. Duas se conheceram em uma festa e passaram a morar juntas. Outras se conheceram por frequentarem o mesmo curso, entrando em contato na sala de aula. Houve o caso do amigo ser colega de um amigo que já estava no Brasil, ou conhecer um primo ou prima desse amigo antes de conhecê-lo. Por vezes, deixam claro que esse encontro se deu na própria universidade.

Quanto aos episódios marcantes, alguns participantes se referiram a mais de um tipo de episódio. Vinte e uma amizades foram marcadas pelo apoio ou companheirismo, como a possibilidade de conviver com alguém brincalhão, o fato de $\mathrm{o}$ amigo ter saído em defesa do outro em sua ausência, a convivência durante a adolescência, podendo discutir os assuntos da adolescência com a amiga, o companheirismo nos momentos de solidão e longe da família, a solidariedade demonstrada quando o participante quebrou o braço, o compartilhar a vida (inclusive ter vindo estudar no Brasil por causa da amiga), o fato de ter sido o primeiro amigo no Brasil (onde não conhecia ninguém).

Em 20 amizades, as atividades de lazer foram marcantes, incluindo incluíam viajar juntos para passar as férias com a família (no Brasil ou em Cabo Verde), viajar com o amigo para outro Estado do Brasil, passar férias juntos em Vitória, passar férias com a amiga em outra cidade. Em relação ao estudo, mencionaram momentos de passagem, como a formatura juntamente com a amiga, os preparativos para a viagem ao Brasil. Em um caso, a amizade foi marcada por sua passagem para uma relação de namoro. Em oito amizades foram marcantes episódios de estudo ou trabalho.

Quanto ao último contato com o amigo próximo, 23 foram pessoais, quatro por telefone e oito pela internet. Quanto ao tempo em que esse contato se deu, 31 haviam feito contato dentro da semana e quatro entre uma semana e um mês.

A maior parte das amizades (14) não apresentava dificuldades. Em 13 delas, as dificuldades estavam relacionadas à distância e, ainda, à comunicação (5), características pessoais ou de personalidade (5) e diferenças culturais (1). As dificuldades de comunicação incluíam situações em que se fala uma coisa e o outro interpreta de forma incorreta ou fala-se alguma coisa e o outro discorda. As características pessoais ou de personalidade incluem ter um temperamento diferente, ser um pouco esquentada, meio ciumenta, teimosa, nervosa, exaltada, estressada ou o fato de ser tímido e fechado e mesmo gostar de coisas diferentes. Apesar da maior parte dos amigos viver no Brasil, a distância ainda é apontada como uma dificuldade. Entre as situações que deram origem a dificuldades estava o fato do amigo querer começar um relacionamento romântico. Referiram-se a brigas, sempre seguidas pela reconciliação. Ainda consideraram as "briguinhas" como algo comum entre pessoas que dividem o quarto.

Vinte amizades foram vistas como influenciando positivamente a adaptação ao Brasil. Três amizades mais próximas haviam exercido uma influência negativa e não reconheceram a influência de 12 amizades. A ajuda na adaptação ia desde ações práticas, como recepcionar e levar o recém-chegado para tirar os documentos, servir de guia para mostrar as coisas em Vitória e no País, quanto a lugares e pessoas (ajuda dos veteranos que estão no Brasil). Em outro caso, a chegada de um amigo melhorou o próprio rendimento nos estudos e na aprendizagem. Outra amiga também forneceu apoio emocional em momentos de saudade de casa, completando uma à outra. Em outro caso, a participante reconhece ter sido difícil deixar pai e mãe, mas as amigas se apoiavam mutuamente, também para aguentar a saudade de casa.

Uma das participantes indicou que o fato da amiga também ser de Cabo Verde propiciava maior contato, pois falavam a mesma língua, enfrentavam os mesmos problemas estando longe da família. Em um dos poucos casos de amizade com brasileiros, a amiga brasileira mostrava tudo de bom e de ruim do Brasil à amiga de Cabo Verde. Outro indicou o papel do amigo para ajudar em sua socialização no Brasil, procurando "enturmá-lo", por ser calado. Amigos que já conheciam a cidade mostravam vários lugares e apresentavam pessoas. Em outro caso, a participante disse que ter uma amiga próxima, dividindo os problemas, ajudou. Outra ainda citou que a comunicação com uma amiga que passava pela mesma situação difícil foi de ajuda para sua adaptação ao Brasil. Uma amiga melhorou a adaptação da participante ao promover sua integração com outras pessoas.

Nos poucos casos em que amigos foram considerados afetar negativamente a adaptação, isto se deu em virtude de as amigas estarem distantes, gerando o sentimento de falta de companhia. O afastamento 
de amigos causou dificuldades no Brasil. Após isso, alguns mantiveram contato e se apoiaram mutuamente. No sentido negativo, os amigos distantes despertavam a vontade de voltar, de estar com eles, por vezes atrapalhando a adaptação no Brasil.

Em alguns casos, a justificativa para a amizade não ter afetado a adaptação ao Brasil foi o fato de o amigo ter chegado ao País após o próprio participante. Outro motivo para não haver influência foi a semelhança entre Cabo Verde e Brasil, não criando dificuldade de adaptação. Além do papel do amigo na adaptação ao Brasil, alguns tiveram um papel também ao atrair o amigo para vir estudar no País.

Em relação à influência dos amigos sobre a forma como eles viam o Brasil, reconheceram influência positiva em 15 amizades. Por outro lado, 20 amizades não afetaram a forma como viam o Brasil. Das 35 amizades mais próximas, apenas quatro eram com brasileiros. Quando não viam influência, porvezes alegavam que já tinham uma opinião formada antes de vir para o Brasil. Como essas amizades próximas, geralmente, eram com outros cabo-verdianos, raramente consideraram a amizade com brasileiros nesse sentido. Em um caso, a amiga brasileira "mostrou que os brasileiros são pessoas super simpáticas e estão aí sempre pra ajudar" (E2). Em geral, uma influência positiva sobre a visão que tinham do Brasil vinha de um olhar diferente em relação ao País. Por vezes, referem-se ao fato de o amigo ter mostrado aspectos positivos, como as belezas naturais. Por outro lado, os amigos também alteraram a visão sobre questões sociais brasileiras:

Passei avero Brasilcom outros olhos, com mais ternura. Porque en criticava muito de inicio, principalmente quando eu via que a maioria de pessoas que limpam as ruas é negro, que é a minha origem. Então eu ficava muito mal, super chateada (E1).

Por vezes, destacam a experiência do outro e seu papel em melhorar a imagem que os caboverdianos têm do Brasil, de um país violento com muita discriminação, mostrando a possibilidade de se viver tranquilamente no País. Em outro caso, mudou as perspectivas e a maneira de pensar do participante em relação ao povo brasileiro.

\section{Discussão}

A rede mais ampla e a rede de amigos mais próximos incluem principalmente outros estudantes cabo-verdianos e, em menor proporção, brasileiros. A tendência a fazer amigos com pessoas do mesmo País tem sido observada em diversos estudos sobre amizades de estudantes internacionais (Bailey, 2006; Brown, 2009a, Pandian, 2008; Cushner \& Karim, 2004; Sawir et al. 2008; United Kingdom Council for International Education, 2004). Possivelmente, a identificação étnica e racial seja um fator importante na escolha de amigos, como proposto por Kao e Vaquera (2006) e Antonio (2004). A maioria dos amigos reside na mesma área que os participantes ou em outros locais do Brasil. Assim, os amigos mais próximos do ponto de vista afetivo também estão, em sua maioria, mais próximos fisicamente. Contudo, também citaram amigos do país de origem ou em outros países.

Em relações aos amigos mais próximos, 24 haviam sido conhecidos em Cabo Verde e 11 no Brasil. Os estudantes de Cabo Verde, já residentes no Brasil, tornaram-se amigos desses novos estudantes e participaram ativamente na mediação das novas amizades desses universitários chegando ao País. Isso aponta a importância do ambiente universitário para as amizades desses estudantes.

Os estudos e atividades de lazer foram interesses em comum e atividades compartilhadas com amigos. Segundo Kao e Joyner (2004), a identificação racial afeta os laços de amizade e as atividades compartilhadas. A presença do estudo como um interesse compartilhado possivelmente deve-se ao fato de compartilharem com a maior parte dos amigos a situação de estudantes internacionais com a meta de se formarem e retornarem ao país de origem.

Alguns aspectos foram investigados somente com relação aos amigos mais próximos. Esses foram descritos principalmente com base em suas características pessoais, no seu significado para o participante, em aspectos do relacionamento com o participante. Os significados atribuídos ao amigo incluíram a consideração da amizade como um valor de destaque, o papel do amigo como alguém que ajuda nos momentos de necessidade e mesmo a consideração do amigo como um ente familiar, especialmente irmão, mas também pai e filho, indicando uma grande proximidade. Essa valorização da amizade pelos estudantes africanos coincide com os valores reconhecidos por brasileiros, que incluem a amizade verdadeira, referindo-se a amigos próximos e apoiadores, entre seus valores supremos, ao lado da harmonia interior, da liberdade e do trabalho (Tamayo, 2007). 
Em relação às dificuldades nas amizades, estas estavam ausentes em quase metade (14) das amizades citadas e foram atribuídas principalmente à distância entre amigos. Isso, possivelmente, está associado ao fato de 14 dos amigos mais próximos não residirem em Vitória. Entre os episódios marcantes, destacam-se episódios de lazer e de apoio e companheirismo, sugerindo que os amigos contribuem efetivamente para o seu bem-estar no País.

A maioria das amizades próximas (23) foi reconhecida como afetando a adaptação ao Brasil, geralmente de forma positiva, com o amigo agindo como um tipo de guia no País (em termos geográficos e sociais), ajudando a socialização, fornecendo apoio emocional nas dificuldades relativas à distância de casa e em situações práticas, como na aquisição de documentação que necessitam assim que chegam ao Brasil. Entre os fatores possíveis, essas amizades poderiam estar associadas ao desenvolvimento de maior sensibilidade multicultural e maior competência social para enfrentar essa nova situação (Hunter \& Elias, 1999). Por outro lado, a maioria das amizades próximas não foi reconhecida como afetando a forma como viam o Brasil, o que pode ser atribuído ao fato de poucas das amizades citadas serem com brasileiros.

No caso destes estudantes de Cabo Verde, o contato com outros estudantes do mesmo país residindo no Brasil há mais tempo parece ser um importante ponto de referência para os novos estudantes que chegam ao País. Apesar de a maioria dos amigos ser da mesma nacionalidade, os dados indicam a existência de algumas amizades com brasileiros e outros africanos, mesmo entre as amizades mais próximas, indicando a possibilidade de formação de relacionamentos interculturais.

Apesar das amizades com pessoas do próprio país fornecerem elementos importantes para esses estudantes (Maundeni, 2001; Zhao \& Wildemeersch, 2008), uma meta a ser buscada seria uma melhor integração à comunidade local por meio de amizades. Quanto à integração com a comunidade brasileira local, ainda há muito a ser feito. Há a necessidade de se aumentar o contato e as relações de amizade entre esses estudantes e os universitários brasileiros e de outras nacionalidades, buscando maior integração social, cultural e científica desses universitários, com possíveis repercussões no aumento da cooperação cultural e científica entre o Brasil e seus países de origem. Essa integração com brasileiros por meio de amizades tem sido reconhecida como uma das principais dificuldades de universitários africanos no Brasil (Desidério, 2006) e a integração e amizade com os brasileiros, quando ocorrem, são reconhecidas como fatores positivos da experiência sociocultural de universitários africanos no Brasil (Subuhana, 2009).

Apesar de alguns autores terem apontado para resultados abaixo do esperado em relação à melhoria nas habilidades transculturais ou no aumento da competência intercultural como resultado do contato desses estudantes com pessoas de outros países (Ward, 2001; Brown, 2009b), os dados sugerem que amizades podem aumentar a tolerância em relação a outras culturas (Cushner \& Karim, 2004) e mesmo ajudar a construir uma imagem mais positiva do país anfitrião.

Conforme proposto por Hinde (1997), diversos níveis de complexidade se manifestam nas amizades dos universitários estrangeiros no Brasil. Os grupos dos quais participam, as estruturas socioculturais e o próprio ambiente físico exercem um papel em suas amizades. Em concordância com Adams e Blieszner (1994), a investigação de amizades interculturais e internacionais deve incluir não somente aspectos internos, mas também externos, ao lado de aspectos estruturais e processuais.

\section{Consideraçóes finais}

Pode-se concluir que as amizades de universitários estrangeiros representam um fator relevante não apenas para a qualidade de vida destes estudantes no Brasil, mas afetam sua integração social, cultural e acadêmica, sendo um aspecto que deveria ser levado em conta nos programas que envolvem estudantes estrangeiros. Os dados também indicam uma integração limitada desses estudantes na comunidade brasileira local, o que deveria ser estimulado. Estudos futuros poderiam aprofundar alguns temas investigados neste trabalho, assim como buscar a participação de um número maior de universitários estrangeiros. Para isso, é necessário contornar dificuldades encontradas na presente pesquisa, especialmente quanto à dificuldade de contato com esses estudantes.

\section{Agradecimento}

Ao Conselho Nacional de Desenvolvimento Científico e Tecnológico (CNPq), peloapoio financeiro. 


\section{Referências}

Adams, R. G., \& Blieszner, R. (1994). An integrative conceptual framework for friendship research. Journal of Social and Personal Relationships, 11(2), 163-184.

Antonio, A. L. (2004). When does race matter in college friendships? Exploring men's diverse and homogeneous friendship groups. Review of Higher Education: Journal of the Association for the Study of Higher Education, 27(4), 553-575.

Bailey, C. (2006). Supporting international students inUK Higher Education: Key issues, and recommendations for further research. Wolverhampton: University of Wolverhampton Learning and Teaching Projects.

Bardin,L. (1977). Análise de conteúdo. Porto: Edições 70.

Brown, L. (2008). Language and anxiety: An ethnographic study of international postgraduate students. Evaluation and Research in Education, 2(3), 75-95.

Brown, L. (2009a). An ethnographic study of the friendship patterns of international students in England: An attempt to recreate home through conational interaction. International Journal of Educational Research, 48(3), 184-193.

Brown, L. (2009b). International education: A force for peace and cross-cultural understanding? Journal of Peace Education, 6(2), 209-224.

Cushner, K., \& Karim, A. U. (2004). Study abroad at university level. In D. Landis; J. M. Bennett; \& M. J. Bennett (Org.). Handbook for Intercultural Training (pp.147-165). Thousand Oaks: Sage.

Desidério, E. de J. (2006). Migração internacional com fins de estudo: ocaso dos africanos do ProgramaEstudanteConvênio de Graduação em três universidades públicas no Rio de Janeiro. Dissertação de Mestrado, IBGE/ Instituto Brasileiro de Geografia e Estatística ENCE/ Escola Nacional de Ciências Estatísticas, Rio de Janeiro.

Hinde, R. A. (1997). Relationships: A dialectical perspective. Hove: Psychology Press.

Hunter, L., \& Elias, M. J. (1999). Interracial friendships, multicultural sensitivity, and social competence: How are they related? Journal of Applied Developmental Psychology, 20(4), 551-573.

Jacobson, C. K., \& Johnson, B. R. (2006). Interracial friendship and African American attitudes about interracial marriage. Journal of Black Studies, 36(4), 570-584.
Kao, G. \& Joyner, K. (2004). Do race and ethnicity matter among friends? Activities among interracial, interethnic, and intraethnic adolescent friends. Sociological Quarterly, 45(3), 557-573.

Kao, G., \& Vaquera, E. (2006). The salience of racial and ethnic identification in friendship choices among hispanic adolescents. Hispanic Journal of Behavioral Sciences, 28(1), 23-47.

Maundeni, T. (2001). The role of social networks in the adjustment of African students to British society: Students' perception. Race, Ethnicity and Education, 4(3), 253-276.

Pandian, A. (2008). Multiculturalism in higher education: A case study of middle eastern students' perceptions and experiences in a Malaysian University. International Journal of Asia Pacific Studies, 4(1), 33-59.

Sawir, E., Marginson, S., Deumert, A., Nyland, C., \& Ramia, G. (2008). Loneliness and international students: An Australian Study. Journal of Studies in International Education, 12(2), 148-180.

Subuhana, C. (2009). A experiência sociocultural de universitários da África lusófona no Brasil: Entremeando histórias. Pro-Posições, 20(1), 103-126.

Tamayo, A. (2007). Hierarquia de valores transculturais e brasileiros. Psicologia: Teoria e Pesquisa, 23(1), 7-15.

United Kingdom Council for International Education (2004). Broadening our horizons. Londres: UKCOSA.

Ward, C. (2001). The impact of international students on domestic students and host institutions. Wellington: New Zealand Ministry of Education.

Ward, C., Bochner, S., \& Furnham, A. (2001). The psychology of culture shock. Londres: Routledge.

Zhao, M., \& Wildemeersch, D. (2008). Hosting foreign students in European universities: International and intercultural perspectives. European Education, 40(1), 51-62.

Recebido: 02/02/2010

Received: 02/02/2010

Aprovado: 19/05/2010

Approved: 05/19/2010 